\title{
Predictors of usage and fatty acid composition of cooking fats in Bogotá, Colombia
}

Ana Baylin ${ }^{1, *}$, Mercedes Mora-Plazas ${ }^{2}$, Olga Cobos-de Rangel ${ }^{2}$, Sandra Lopez-

Arana $^{2}$, Hannia Campos ${ }^{3}$ and Eduardo Villamor ${ }^{3,4}$

'Department of Community Health, Warren Alpert Medical School, Brown University, Box G-S121, Providence, RI 02903, USA: ${ }^{2}$ Department of Nutrition, National University of Colombia, Bogotá, Colombia: ${ }^{3}$ Department of Nutrition, Harvard School of Public Health, Boston, MA, USA: ${ }^{4}$ Department of Epidemiology, Harvard School of Public Health, Boston, MA, USA

Submitted 2 August 2007: Accepted 6 March 2008: First published online 22 April 2008

\begin{abstract}
Objective: To examine correlates of home usage of commercially available cooking fats in Bogotá, Colombia and to determine their fatty acid composition. Design: Cross-sectional survey.

Setting: Bogotá, Colombia.

Subjects: A representative sample of low- and middle-income families ( $n$ 2408). Results: The types of fat primarily used for cooking at home were mixed vegetable oils (66\%), sunflower oil (21\%) and other oils/fats including margarine (13\%). In multivariate analysis, usage of sunflower oil as the primary cooking fat was positively related to home ownership, age of the father and health as a reason for choosing the main cooking fat, and inversely associated with the number of people per room and an index of household food insecurity. The trans fat content of sunflower oil was unexpectedly higher (mean $4 \cdot 2 \%$, range $2 \cdot 2-8 \cdot 6$ ) than that of the vegetable mixture oils (mean $3 \cdot 1 \%$, range $1 \cdot 1-6 \cdot 5$ ).

Conclusions: Vegetable oils are the primary home cooking fats in Bogotá, Colombia. Higher socio-economic status is associated with usage of sunflower oil. Paradoxically, oblivious to the higher trans content of sunflower oil and the negligible amount of $n-3$ fatty acids, families commonly reported 'health' as a reason to choose sunflower over other oils.
\end{abstract}

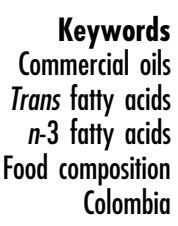

There is compelling evidence that trans fatty acid intake increases the risk of $\mathrm{CHD}^{(1-4)}$. Trans fatty acid intake is also associated with diabetes and possibly with obesity ${ }^{(5-7)}$. In a recent meeting, a Pan American Health Organization (PAHO)/WHO task force called for the elimination of trans fatty acids from the food supply in the Americas and recommended that unsaturated fats should be the preferred alternative, including $n-3$ PUFA $^{(4)}$. However, little is known about the intake of trans fatty acids or $n$-3 PUFA in many Latin American countries.

The oil or fat used for cooking at home is one of the main and regular sources of fatty acids in the diet. Furthermore, Latin American countries are experiencing a nutrition transition towards a higher intake of edible oils ${ }^{(8)}$. The most widely used oils in Latin America are soyabean oil and palm oil, followed by corn oil in Central America and sunflower in South America ${ }^{(9)}$. These oils are usually mixed, partially hydrogenated and marketed as vegetable oils. Therefore the amount of specific fatty acids (like trans fatty acids or $n-3$ PUFA) is often unknown. If PAHO recommendations are to be followed, more information on the predictors of intake and composition of cooking oils and fats is required from these populations $^{(4)}$. We conducted a study among low- and middle-income families from Bogotá, Colombia, in order to determine the most commonly used cooking fats and oils, the correlates of usage and the fatty acid composition of the most commonly available cooking oils and fats.

\section{Materials and methods}

\section{Study population}

We conducted a survey of cooking fats use and intake in families from Bogotá, as part of an ongoing nutrition study of primary-school children. In the present study, we recruited a representative sample of children aged 5 to 12 years who were enrolled in the public primary school system by February 2006. A cluster random sampling strategy was used, where clusters were defined as the classes of all 361 public primary schools in the city by the end of 2005. We randomly selected 166 classes out of a 
total of 8500 identified, to reach the target sample size of 4000 children. During the first week of February, we sought consent to participate in the study and obtained a positive response from 3032 families corresponding to 3202 children. The primary schooling coverage in Bogotá is high ( $88 \%$ in 2005). The majority of children of primary school age in the city (57\%) are enrolled in the public school system. Most of these children (89\%) are from low- and middle-income families ${ }^{(10)}$. Our survey is therefore representative of low- and middle-income families from Bogotá who had children enrolled in the public primary school system in 2006.

\section{Data collection}

We collected baseline information from the children's families with the use of a self-administered questionnaire that was to be completed by the mother or primary care provider. Only one questionnaire was filled in per household. This questionnaire included questions on maternal age, education, parity, marital status, paternal age and education, indicators of household socio-economic status and a sixteen-item food security assessment survey, modified from the US Household Food Security Module $^{(11)}$. This form also included questions on the main type of oil or fat that was most commonly used for cooking at home and the reasons for using it.

To identify the fatty acid content of the most used oils, we obtained samples of all commercially available oils and fats commonly consumed in Colombia from supermarkets and neighbourhood markets in Bogotá. Samples were aliquoted into $2 \mathrm{ml}$ glass vials with Teflon caps and stored at $-80^{\circ} \mathrm{C}$ until analysis at the Biomarker Analysis Laboratory at the Harvard School of Public Health.

The study was approved by the Human Subjects Committee of the Harvard School of Public Health and the Ethics Committee of the National University of Colombia Medical School.

\section{Operational definitions}

The number of samples analysed for each type of oil or fat was as follows: six for sunflower oil, eleven for mixed vegetable oils, two for palm shortening, two for canola oil, nine for margarines and two for butter. Mixed vegetable oils are mixtures of soyabean oil, corn oil and palm oil mostly, and are marketed as vegetable oils.

\section{Fatty acid analysis}

Lipids that contained non-esterified or esterified fatty acids were extracted from $2 \mathrm{ml}$ of hexane-isopropanol mixture $(3: 2, \mathrm{v} / \mathrm{v})$ or $2 \mathrm{ml}$ of $6 \%$ sodium sulfate mixture containing the sample. Fatty acids were esterified with a methylating reagent containing methanol $(2 \mathrm{ml})$ and acetyl chloride $(0 \cdot 1 \mathrm{ml})$ as previously described ${ }^{(12,13)}$. After esterification, the methanol and acetyl chloride were evaporated off and the fatty acid methyl esters were redissolved in isooctane. Fatty acids were determined by GC, using the same conditions as in our previous studies $^{(12,13)}$. Peak retention times and area percentages of total fatty acids were identified by injecting known standards (NuCheck Prep, Elysium, MN, USA) and analysed with the ChemStation A.08.03 software from Agilent Technologies (Foster City, CA, USA). A total of forty-six fatty acids were analysed. As part of the laboratory quality control, a control oil sample was run periodically. CV for the main fatty acids were: 1.58 for $16: 0,0 \cdot 25$ for $18: 0$, $0 \cdot 10$ for $18: 1 n-9,0.63$ for $18: 2 n-6,0.97$ for $18: 3 n-6$ and $0 \cdot 52$ for $c, t-18: 2 n-6$.

\section{Statistical analyses}

The baseline survey was filled in and returned by 2466 of the households enrolled (81\%). We excluded fifty-eight questionnaires that lacked information on the main variable of interest (primary cooking fat); hence the final sample size was 2408 .

The primary endpoint of interest was the main type of oil or fat used for cooking at home. Predictors included demographic characteristics of the mothers and fathers, indicators of household socio-economic status and food insecurity. The latter was categorized into four groups according to the sum of affirmative responses to the sixteen-item survey: food-secure (one or two affirmative responses), food-insecure without hunger (three to five affirmative responses), food-insecure with moderate hunger (six to twelve affirmative responses) or foodinsecure with severe hunger (thirteen or more affirmative responses).

We assessed the significance of differences in sociodemographic characteristics by type of primary cooking oil with the use of $\chi^{2}$ and ANOVA tests for categorical and continuous variables, respectively. Pairwise comparisons were adjusted using the Bonferroni method. Owing to its unexpected high content of trans fatty acids, we next evaluated predictors of sunflower oil use. We estimated adjusted prevalence ratios for sunflower oil use and $95 \%$ confidence intervals with the use of a generalized estimating equation with the log-binomial distribution specification. An exchangeable correlation structure was applied to account for clustering due to sampling. In this model, we introduced as predictors the variables that were significantly associated with sunflower oil use in univariate analysis. All data were analysed with the Statistical Analysis Systems statistical software package (SAS Institute Inc., Cary, NC, USA).

\section{Results}

Most families consumed mixed vegetable oils (66\%), followed by sunflower oil (21\%) and other oils/fats (13\%), which included mostly palm shortening, margarine and others. Canola oil has recently been introduced on the market and is not yet highly consumed $(0 \cdot 17 \%)$. 
Table 1 Sociodemographic characteristics by primary type of oil used for cooking at home: low- and middle-income families with children enrolled in the public primary school system, Bogotá, Colombia, 2006

\begin{tabular}{|c|c|c|c|c|c|c|c|}
\hline \multirow[b]{2}{*}{ Characteristic } & \multicolumn{2}{|c|}{$\begin{array}{l}\text { Mixed oils* } \\
(n \text { 1579) }\end{array}$} & \multicolumn{2}{|c|}{$\begin{array}{l}\text { Sunflower oil } \\
\text { (n 505) }\end{array}$} & \multicolumn{2}{|c|}{$\begin{array}{l}\text { Other oils/fats } \\
\qquad(n \text { 324) }\end{array}$} & \multirow[b]{2}{*}{$P+$} \\
\hline & Mean & SD & Mean & SD & Mean & SD & \\
\hline Mother's age (years) & $35 \cdot 0^{\mathrm{a}}$ & $6 \cdot 8$ & $36 \cdot 2^{b}$ & $7 \cdot 0$ & $35 \cdot 5^{\mathrm{a}, \mathrm{b}}$ & $6 \cdot 5$ & 0.004 \\
\hline Mother's education (years) & $8 \cdot 6^{\mathrm{a}}$ & $3 \cdot 2$ & $9 \cdot 0^{\mathrm{a}}$ & $3 \cdot 3$ & $8 \cdot 1^{\mathrm{b}}$ & 3.5 & 0.0002 \\
\hline Father's age (years) & $38 \cdot 4^{\mathrm{a}}$ & $8 \cdot \overline{0}$ & $40 \cdot 0^{\mathrm{b}}$ & $8 \cdot 6$ & $38 \cdot 9^{\mathrm{a}, \mathrm{b}}$ & $8 \cdot 2$ & 0.001 \\
\hline Number of people at home & $4 \cdot 9$ & 1.9 & $4 \cdot 9$ & $2 \cdot 0$ & $5 \cdot 2$ & $2 \cdot 1$ & 0.09 \\
\hline Average daily income per person (\$US) $\ddagger$ & $1 \cdot 8^{\mathrm{a}}$ & $1 \cdot 0$ & $2 \cdot 2^{\mathrm{b}}$ & $1 \cdot 7$ & $1 \cdot 5^{\mathrm{c}}$ & $1 \cdot 2$ & $<0.0001$ \\
\hline Monthly amount of money spent on food at home (\$US) & $104^{\mathrm{a}}$ & 56 & $124^{\mathrm{b}}$ & 77 & $95^{\mathrm{a}}$ & 58 & $<0.0001$ \\
\hline Percentage of family income allocated to food per month & $47 \cdot 3$ & $22 \cdot 7$ & $47 \cdot 3$ & $21 \cdot 7$ & $48 \cdot 0$ & $25 \cdot 6$ & 0.90 \\
\hline Average daily amount of money spent on food per person (\$US) & $0.77^{\mathrm{a}}$ & 0.45 & $0.91^{\mathrm{b}}$ & 0.52 & $0.66^{\mathrm{c}}$ & 0.43 & $<0.0001$ \\
\hline Average number of people sleeping in a room & $2 \cdot 6^{\mathrm{a}}$ & $1 \cdot 4$ & $2 \cdot 2^{\mathrm{b}}$ & $1 \cdot 3$ & $2 \cdot 8^{\mathrm{c}}$ & $1 \cdot 4$ & $<0.0001$ \\
\hline Number of household assets§ & $3 \cdot 9^{a}$ & 1.6 & $4 \cdot 4^{b}$ & $1 \cdot 6$ & $3 \cdot 5^{\mathrm{c}}$ & $1 \cdot 7$ & $<0.0001$ \\
\hline Mother is married (\%) & \multicolumn{2}{|c|}{$25 \cdot 9$} & \multicolumn{2}{|c|}{$28 \cdot 6$} & \multicolumn{2}{|c|}{$26 \cdot 3$} & 0.49 \\
\hline Home ownership (\%) & \multicolumn{2}{|c|}{$31 \cdot 2^{\mathrm{a}}$} & \multicolumn{2}{|c|}{$43 \cdot 2^{b}$} & \multicolumn{2}{|c|}{$26 \cdot 3^{\mathrm{a}, \mathrm{c}}$} & $<0.0001$ \\
\hline Food insecurity index & \multirow{2}{*}{\multicolumn{2}{|c|}{$22 \cdot 5^{\mathrm{a}}$}} & & & & & $<0.0001$ \\
\hline Food-secure (\%) & & & \multicolumn{2}{|c|}{$32 \cdot 4^{\mathrm{b}}$} & \multicolumn{2}{|c|}{$15 \cdot 4^{\mathrm{c}}$} & \\
\hline Food-insecure without hunger (\%) & \multicolumn{2}{|c|}{$48 \cdot 0^{\mathrm{a}}$} & \multicolumn{2}{|c|}{$49 \cdot 1^{a, b}$} & \multicolumn{2}{|c|}{$38 \cdot 6^{\mathrm{c}}$} & \\
\hline Food-insecure with moderate hunger (\%) & \multicolumn{2}{|c|}{$19 \cdot 2^{\mathrm{a}}$} & \multicolumn{2}{|c|}{$13 \cdot 6^{\mathrm{b}}$} & \multicolumn{2}{|c|}{$20 \cdot 6^{\mathrm{a}, \mathrm{b}}$} & \\
\hline Food-insecure with severe hunger (\%) & \multicolumn{2}{|c|}{$10 \cdot 3^{\mathrm{a}}$} & \multicolumn{2}{|c|}{$4 \cdot 9^{\mathrm{b}}$} & \multicolumn{2}{|c|}{$25 \cdot 5^{\mathrm{c}}$} & \\
\hline \multicolumn{8}{|l|}{ Reasons to use main type of oil/fat for cooking } \\
\hline Price (\%) & \multicolumn{2}{|c|}{$65 \cdot 7^{\mathrm{a}}$} & \multicolumn{2}{|c|}{$37 \cdot 3^{\mathrm{b}}$} & \multicolumn{2}{|c|}{$77 \cdot 7^{\mathrm{c}}$} & $<0.0001$ \\
\hline Health (\%) & \multirow{2}{*}{\multicolumn{2}{|c|}{$\begin{array}{r}9 \cdot 0^{\mathrm{a}} \\
25 \cdot 0^{\mathrm{a}}\end{array}$}} & \multicolumn{2}{|c|}{$28 \cdot 6^{b}$} & \multicolumn{2}{|c|}{$11 \cdot 0^{\mathrm{a}, \mathrm{c}}$} & $<0.0001$ \\
\hline Taste (\%) & & & \multicolumn{2}{|c|}{$47 \cdot 1^{\mathrm{b}}$} & \multicolumn{2}{|c|}{$21 \cdot 0^{\mathrm{a}, \mathrm{c}}$} & $<0.0001$ \\
\hline Quality (\%) & \multicolumn{2}{|c|}{$\begin{array}{r}20 \cdot 0 \\
2 \cdot 0\end{array}$} & 2 & & & & 0.06 \\
\hline Tradition (\%) & 31. & & 23 & & 14 & & $<0.0001$ \\
\hline
\end{tabular}

${ }^{a, b, c}$ Mean values within a row with unlike superscript letters were significantly different $(P<0.05)$.

*Mixed oils are mixtures of soyabean oil, corn oil and palm oil mostly, and are marketed as vegetable oils.

tGlobal $P$ values.

$\ddagger$ Conversion exchange rate: Colombian Peso per $\$$ US $=0.00043$ (average during survey dates).

§From a total of six including bike, refrigerator, blender, television, stereo and washing machine.

Olive oil and corn oil (not mixed) are rarely consumed in this population $(0.04 \%$ and $0.08 \%$, respectively). Table 1 presents the sociodemographic characteristics of the population by main type of cooking oil/fat. As expected by the market price (mixed vegetable oils are cheaper than sunflower oil), participants who reported usage of sunflower oil as the primary cooking fat had higher income and education, less food insecurity and spent more money on food than did non-users. Cheaper price was a frequent reason for choosing mixed oils or other oils/fats over sunflower, while health and taste were more common reasons among sunflower oil users.

We next evaluated predictors of sunflower oil use with a multivariate log-binomial model (Table 2). Usage of sunflower oil as the primary cooking fat was positively related to home ownership, age of the father and health reasons, and inversely associated with the number of people per room in the household and an index of household food insecurity.

The fatty acid composition of cooking oils and fats most commonly consumed in Colombia is presented in Table 3. Most of the study participants (86\%) reported one of the thirty-four oils/fats that we analysed as their main type of cooking fat. The remaining $14 \%$ were mostly participants who did not specify a brand name; a minority of families $(n 40)$ reported the use of animal fat as the main cooking fat. The composition of mixed oils likely reflects a mixture of soyabean oil, corn oil and palm oil. Margarines showed high variability in their composition, consistent with a wide variety of margarines on the market including different mixtures of palm, soyabean, sunflower, cotton and canola oils. The proportion of trans fatty acids in margarines ranged from $0.95 \%$ to $10 \cdot 23 \%$. The fatty acid composition of not mixed oils was as expected. However, the content of trans fatty acids in sunflower oil was higher than that in mixed vegetable oils. The amount of trans fatty acids in sunflower and mixed oils varied by brand with a range from $2 \cdot 22 \%$ to $8.64 \%$ for sunflower oil and from $1.11 \%$ to $6.53 \%$ for mixed vegetable oil. Canola oil, although not commonly consumed, is included for comparison purposes and because it is gaining in popularity.

\section{Discussion}

Mixed vegetable oils were the main cooking fat in this population, followed by sunflower oil. Mixed vegetable oils are combinations of soyabean oil, corn oil and palm oil, and therefore contain high percentages of SFA. They are frequently used by the poorest people. The amount of trans fatty acids in sunflower oil was unexpectedly higher than that in mixed vegetable oils. Sunflower oil users appeared to be of higher socio-economic status compared 
Table 2 Predictors of sunflower oil intake by low- and middle-income families with children enrolled in the public primary school system, Bogotá, Colombia, 2006*

\begin{tabular}{|c|c|c|c|}
\hline & $n$ & Adjusted prevalence ratio & $95 \% \mathrm{Cl}$ \\
\hline \multicolumn{4}{|l|}{ Home ownership } \\
\hline No & 1494 & 1.00 & \\
\hline Yes & 746 & $1 \cdot 29$ & $1 \cdot 12,1 \cdot 49$ \\
\hline \multicolumn{4}{|l|}{ Father's aget } \\
\hline$<40$ years & 1254 & 1.00 & \\
\hline$\geq 40$ years & 707 & $1 \cdot 23$ & $1 \cdot 06,1 \cdot 43$ \\
\hline \multicolumn{4}{|l|}{ Food security $\ddagger$} \\
\hline Food-secure & 533 & $1 \cdot 00$ & \\
\hline Food-insecure without hunger & 1056 & 0.89 & $0 \cdot 75,1.06$ \\
\hline Food-insecure with moderate hunger & 408 & $0 \cdot 71$ & $0.54,0.91$ \\
\hline Food-insecure with severe hunger & 243 & 0.44 & $0 \cdot 29,0.67$ \\
\hline \multicolumn{4}{|c|}{ Average number of people sleeping in a room§ } \\
\hline$\leq 2$ & 1216 & 1.00 & \\
\hline 3 & 635 & 0.77 & $0.63,0.94$ \\
\hline 4 & 225 & 0.68 & $0.47,1.00$ \\
\hline$\geq 5$ & 164 & 0.55 & $0 \cdot 36,0.85$ \\
\hline \multicolumn{4}{|c|}{ Health is a reason for using a particular type of oil } \\
\hline No & 1939 & 1.00 & \\
\hline Yes & 301 & $2 \cdot 33$ & $1 \cdot 99,2 \cdot 74$ \\
\hline
\end{tabular}

*Among observations without missing values ( $n$ 2240).

tTwo hundred and seventy-four missing values in the category (indicator method).

$\ddagger$ Adjusted $P$ for trend $<0.0001$.

$\S$ Adjusted $P$ for trend $=0.003$.

with users of other oils. Paradoxically, oblivious to the higher trans fats content of sunflower oil and the negligible amount of $n-3$ PUFA, 'health' was commonly reported as the main reason to choose sunflower over other oils.

The average percentage of trans fatty acids in mixed vegetable oils, sunflower oil and margarines is above current PAHO recommendations $(<2 \% \text { of total fats })^{(4)}$. The content of trans fatty acids in sunflower oil, although not extremely high, is unexpected and higher than that of similar oils marketed in other Latin American countries including Costa Rica and Argentina ${ }^{(13,14)}$. Although sunflower oil is not commonly hydrogenated, it is known that deodorization, a common step in the refining process, can produce trans PUFA ${ }^{(15-17)}$. This is consistent with our finding of a higher proportion of $18: 2$ trans fatty acids in sunflower oil. Thus, we speculate that the reason for the higher-than-expected content of trans fat in Colombian sunflower oil may be the use of high temperatures in the process of deodorization by the industry.

Colombian margarines have, on average, lower concentrations of trans fatty acids than margarines in other Latin American countries ${ }^{(13,14,18)}$; however, they are much higher in SFA. Margarines in Colombia are low in trans fatty acids because they are mostly palm oil-based. All margarines with low trans fat content have, on average, $50 \%$ or more of SFA. Because they are already highly saturated, they do not need further partial hydrogenation and therefore their trans fat content is low. However, the content of trans fatty acids is higher in some margarines with low SFA content (approximately 10\% of trans fatty acids). It should be noted that current recommendations call for a decrease in the trans fatty acids content of margarines without a concurrent increase in $\mathrm{SFA}^{(19)}$ and efforts from the industry have proved that this is possi$\mathrm{ble}^{(20)}$. Even though margarine is not commonly reported as the main cooking fat (only by $2 \cdot 7 \%$ of the families), it is often reported as a secondary cooking fat (by $16.5 \%$ ) and, consequently, it is an important source of trans fatty acids and SFA in Colombia.

As reported in a study among ninety-seven adults of the region of Santander in Colombia, dietary intake of PUFA is low in this population $(3.7 \%$ of total energy intake) compared with MUFA ( $8 \cdot 1 \%$ of total energy intake) and SFA $(9 \cdot 1 \% \text { of total energy intake })^{(21)}$. Furthermore, Colombia has one of the lowest intakes of long-chain $n$-3 fatty acids worldwide ${ }^{(22)}$. Therefore, the amount of $\alpha$-linolenic acid (an essential $n$-3 PUFA) in commercially available fats and oils in Colombia is particularly critical in this population, since it might represent their main source of $n-3$ PUFA. Mixed vegetable oils and canola oil would be the best sources of $n-3$ fatty acids for this population, although canola oil is still an expensive commodity. Interestingly, people of higher socio-economic status, who could afford more expensive options, tended to prefer sunflower oil, which has negligible amounts of $n-3$ fatty acids. We did not collect specific information on why families perceive sunflower oil as a healthier option but it is unlikely that they are aware of the fatty acid composition of these oils and their health effects. Therefore, our data are in agreement with the well-known role of industry in influencing people's behaviour through advertising ${ }^{(23)}$.

The Colombian population will likely benefit from a mixed vegetable oil with higher concentration of $\alpha$-linolenic acid and lower trans and saturated fatty acid contents at an 
Table 3 Fatty acid composition $(\mathrm{g} / 100 \mathrm{~g})$ of the most frequently consumed oils and fats in Colombia

\begin{tabular}{|c|c|c|c|c|c|c|c|c|c|c|c|c|}
\hline & \multicolumn{2}{|c|}{ Mixed oils ( $n$ 12) } & \multicolumn{2}{|c|}{ Sunflower $(n 6)$} & \multicolumn{2}{|c|}{ Palm $(n 3)$} & \multicolumn{2}{|c|}{ Canola (n 2) } & \multicolumn{2}{|c|}{ Margarine $(n 9)$} & \multicolumn{2}{|c|}{ Butter ( $n$ 2) } \\
\hline & Mean & SD & Mean & SD & Mean & SD & Mean & SD & Mean & SD & Mean & SD \\
\hline \multicolumn{13}{|l|}{ SFA } \\
\hline 8:0 & 0.00 & 0.00 & 0.00 & 0.00 & 0.00 & 0.00 & 0.00 & 0.00 & 0.00 & 0.00 & 0.14 & $0 \cdot 13$ \\
\hline $10: 0$ & 0.00 & 0.00 & 0.00 & 0.00 & 0.17 & 0.20 & 0.00 & 0.00 & 0.12 & 0.15 & 0.83 & 0.23 \\
\hline $12: 0$ & 0.08 & 0.06 & 0.01 & 0.02 & $4 \cdot 60$ & $5 \cdot 49$ & 0.02 & 0.00 & $3 \cdot 61$ & $3 \cdot 70$ & 2.03 & 0.01 \\
\hline $13: 0$ & 0.00 & 0.00 & 0.00 & 0.00 & 0.00 & 0.00 & 0.00 & 0.00 & 0.00 & 0.00 & 0.12 & 0.00 \\
\hline $14: 0$ & 0.23 & $0 \cdot 10$ & 0.08 & 0.04 & $2 \cdot 37$ & $1 \cdot 81$ & 0.07 & 0.01 & 1.91 & $1 \cdot 43$ & $10 \cdot 13$ & 0.05 \\
\hline $15: 0$ & 0.02 & 0.00 & 0.02 & 0.00 & 0.05 & 0.00 & 0.02 & 0.00 & 0.04 & 0.01 & $1 \cdot 48$ & 0.05 \\
\hline $16: 0$ & $15 \cdot 30$ & $2 \cdot 54$ & $5 \cdot 84$ & 0.56 & 38.29 & $2 \cdot 81$ & $4 \cdot 88$ & 0.64 & 30.09 & $12 \cdot 44$ & $29 \cdot 83$ & 0.14 \\
\hline $17: 0$ & 0.09 & 0.01 & 0.05 & 0.01 & 0.09 & 0.01 & 0.07 & 0.00 & 0.09 & 0.01 & $0 \cdot 70$ & 0.19 \\
\hline $18: 0$ & 3.89 & 0.35 & 3.98 & 0.50 & $5 \cdot 43$ & 0.91 & 1.91 & 0.07 & 7.79 & 1.43 & 13.85 & 0.30 \\
\hline $19: 0$ & 0.01 & 0.01 & 0.00 & 0.00 & 0.03 & 0.01 & 0.01 & 0.01 & 0.13 & 0.09 & 0.22 & 0.07 \\
\hline $20: 0$ & $0 \cdot 31$ & 0.03 & 0.23 & 0.02 & 0.28 & 0.02 & $0 \cdot 47$ & 0.00 & 0.30 & 0.03 & 0.14 & 0.01 \\
\hline $21: 0$ & 0.06 & 0.04 & 0.04 & 0.02 & 0.00 & 0.00 & 0.02 & 0.03 & 0.00 & 0.01 & 0.03 & 0.01 \\
\hline $22: 0$ & 0.24 & 0.04 & 0.42 & 0.08 & 0.05 & 0.01 & 0.22 & 0.02 & 0.14 & 0.12 & 0.04 & 0.01 \\
\hline $23: 0$ & 0.02 & 0.02 & 0.02 & 0.01 & 0.01 & 0.01 & 0.00 & 0.00 & 0.01 & 0.01 & 0.01 & 0.01 \\
\hline $24: 0$ & 0.07 & 0.02 & 0.11 & 0.01 & 0.05 & 0.00 & 0.06 & 0.03 & 0.06 & 0.03 & 0.01 & 0.00 \\
\hline Total SFA & $20 \cdot 34$ & $2 \cdot 72$ & $10 \cdot 80$ & $0 \cdot 41$ & $51 \cdot 42$ & $5 \cdot 58$ & $7 \cdot 75$ & 0.74 & $44 \cdot 29$ & 14.84 & 59.55 & 0.11 \\
\hline \multicolumn{13}{|l|}{ MUFA } \\
\hline $14: 1 n-5$ & 0.00 & 0.00 & 0.00 & 0.00 & 0.00 & 0.00 & 0.00 & 0.00 & 0.00 & 0.00 & 0.80 & 0.00 \\
\hline $15: 1 n-5$ & 0.00 & 0.00 & 0.00 & 0.00 & 0.00 & 0.00 & 0.00 & 0.00 & 0.00 & 0.00 & 0.00 & 0.00 \\
\hline $16: 1 n-7$ & $0 \cdot 10$ & 0.01 & 0.08 & 0.02 & $0 \cdot 13$ & 0.03 & 0.26 & 0.01 & $0 \cdot 11$ & 0.02 & 1.59 & $0 \cdot 10$ \\
\hline $17: 1 n-7$ & 0.00 & 0.00 & 0.00 & 0.00 & 0.00 & 0.00 & 0.00 & 0.00 & 0.00 & 0.00 & 0.00 & 0.00 \\
\hline $18: 1 n-9$ & 23.96 & $2 \cdot 81$ & $26 \cdot 55$ & $2 \cdot 01$ & $35 \cdot 70$ & $4 \cdot 68$ & $54 \cdot 66$ & $2 \cdot 20$ & $33 \cdot 74$ & $5 \cdot 59$ & $26 \cdot 19$ & 0.74 \\
\hline $18: 1 n-7$ & $1 \cdot 25$ & 0.07 & 0.58 & 0.11 & 0.60 & 0.03 & $3 \cdot 33$ & 0.27 & $1 \cdot 10$ & 0.76 & 0.42 & 0.00 \\
\hline $20: 1 n-12$ & 0.40 & 0.42 & 0.02 & 0.02 & 0.01 & 0.01 & 0.28 & 0.01 & 0.04 & 0.05 & 0.05 & 0.06 \\
\hline $20: 1 n-9$ & $0 \cdot 15$ & 0.02 & $0 \cdot 12$ & 0.01 & $0 \cdot 11$ & 0.01 & 0.92 & 0.25 & $0 \cdot 17$ & 0.22 & 0.03 & 0.00 \\
\hline $24: 1 n-9$ & 0.01 & 0.01 & 0.02 & 0.04 & 0.00 & 0.01 & 0.08 & 0.05 & 0.02 & 0.03 & 0.00 & 0.01 \\
\hline Total MUFA & $25 \cdot 86$ & $2 \cdot 48$ & $27 \cdot 38$ & $2 \cdot 13$ & 36.55 & $4 \cdot 72$ & $59 \cdot 53$ & $2 \cdot 29$ & $35 \cdot 17$ & $6 \cdot 44$ & $29 \cdot 07$ & $0 \cdot 89$ \\
\hline \multicolumn{13}{|l|}{ PUFA } \\
\hline \multicolumn{13}{|l|}{$n-3$} \\
\hline $18: 3 n-3$ & $3 \cdot 84$ & 0.65 & $0 \cdot 18$ & 0.08 & $0 \cdot 17$ & 0.02 & $7 \cdot 98$ & 0.22 & $0 \cdot 71$ & 1.55 & 0.57 & 0.03 \\
\hline $20: 3 n-3$ & 0.00 & 0.00 & 0.00 & 0.00 & 0.00 & 0.00 & 0.01 & 0.01 & 0.00 & 0.00 & 0.00 & 0.00 \\
\hline $20: 5 n-3$ (EPA) & 0.00 & 0.00 & 0.00 & 0.00 & 0.00 & 0.00 & 0.00 & 0.00 & 0.00 & 0.00 & 0.06 & 0.00 \\
\hline $22: 5 n-3$ (DPA) & 0.00 & 0.00 & 0.00 & 0.00 & 0.00 & 0.00 & 0.00 & 0.00 & 0.00 & 0.00 & 0.09 & 0.01 \\
\hline $22: 6 n-3(\mathrm{DHA})$ & 0.00 & 0.00 & 0.00 & 0.00 & 0.00 & 0.00 & 0.00 & 0.00 & 0.00 & 0.00 & 0.00 & 0.00 \\
\hline Total $n-3$ & $3 \cdot 84$ & 0.65 & $0 \cdot 18$ & 0.08 & $0 \cdot 17$ & 0.02 & $7 \cdot 99$ & 0.23 & $0 \cdot 71$ & $1 \cdot 55$ & 0.72 & 0.02 \\
\hline \multicolumn{13}{|l|}{$n-6$} \\
\hline $18: 2 n-6$ & $46 \cdot 44$ & $3 \cdot 84$ & $57 \cdot 24$ & $4 \cdot 39$ & $9 \cdot 12$ & $2 \cdot 33$ & $22 \cdot 67$ & 1.54 & $11 \cdot 00$ & $8 \cdot 41$ & $1 \cdot 70$ & $0 \cdot 17$ \\
\hline $18: 3 n-6$ & 0.03 & 0.09 & 0.01 & 0.02 & 0.00 & 0.00 & 0.05 & 0.08 & 0.00 & 0.00 & 0.03 & 0.00 \\
\hline $20: 2 n-6$ & 0.02 & 0.01 & 0.00 & 0.01 & 0.00 & 0.00 & 0.07 & 0.01 & 0.00 & 0.01 & 0.01 & 0.01 \\
\hline $20: 3 n-6$ & 0.00 & 0.00 & 0.00 & 0.00 & 0.00 & 0.00 & 0.00 & 0.00 & 0.01 & 0.02 & 0.06 & 0.01 \\
\hline $20: 4 n-6$ & 0.00 & 0.01 & 0.00 & 0.00 & 0.02 & 0.02 & 0.00 & 0.00 & 0.01 & 0.01 & 0.08 & 0.00 \\
\hline $22: 2 n-6$ & 0.00 & 0.01 & 0.00 & 0.00 & 0.00 & 0.00 & 0.00 & 0.01 & 0.00 & 0.00 & 0.00 & 0.00 \\
\hline $22: 4 n-6$ & 0.00 & 0.00 & 0.00 & 0.00 & 0.00 & 0.00 & 0.00 & 0.00 & 0.00 & 0.00 & 0.00 & 0.00 \\
\hline Total $n-6$ & $46 \cdot 50$ & $3 \cdot 88$ & $57 \cdot 25$ & $4 \cdot 37$ & $9 \cdot 14$ & $2 \cdot 33$ & $22 \cdot 80$ & 1.63 & $11 \cdot 02$ & $8 \cdot 40$ & $1 \cdot 87$ & $0 \cdot 16$ \\
\hline \multicolumn{13}{|l|}{$n-7$} \\
\hline$c-18: 2 n-7$ & 0.06 & 0.04 & 0.06 & 0.02 & 0.00 & 0.01 & 0.03 & 0.01 & 0.01 & 0.01 & $1 \cdot 50$ & 0.05 \\
\hline Trans fatty acids & & & & & & & & & & & & \\
\hline$t-18: 1 n-12$ & 0.27 & 0.14 & 0.22 & 0.12 & 0.63 & 0.33 & 0.35 & 0.04 & 1.98 & $1 \cdot 15$ & 0.99 & 0.06 \\
\hline$t-18: 1 n-9$ & 0.25 & $0 \cdot 18$ & $0 \cdot 20$ & $0 \cdot 11$ & 0.33 & 0.23 & $0 \cdot 40$ & 0.08 & $1 \cdot 51$ & $1 \cdot 02$ & $1 \cdot 23$ & 0.24 \\
\hline$t-18: 1 n-7$ & 0.12 & 0.07 & $0 \cdot 13$ & $0 \cdot 11$ & $0 \cdot 16$ & 0.12 & $0 \cdot 18$ & 0.03 & 0.83 & 0.58 & 1.53 & 0.04 \\
\hline Total $t-18: 1$ & 0.63 & 0.36 & 0.55 & 0.31 & $1 \cdot 12$ & 0.68 & 0.93 & $0 \cdot 15$ & $4 \cdot 32$ & $2 \cdot 71$ & 3.75 & 0.26 \\
\hline$t, t-18: 2 n-6$ & 0.09 & 0.06 & 0.11 & 0.06 & 0.02 & 0.01 & 0.05 & 0.01 & 0.06 & 0.04 & 0.01 & 0.01 \\
\hline$c, t-18: 2 n-6$ & $1 \cdot 26$ & 0.71 & $1 \cdot 80$ & $1 \cdot 19$ & 0.26 & 0.03 & 0.43 & 0.03 & 0.42 & 0.39 & $0 \cdot 16$ & 0.00 \\
\hline$t, c-18: 2 n-6$ & $1 \cdot 13$ & $0 \cdot 61$ & $1 \cdot 72$ & $1 \cdot 12$ & 0.24 & 0.03 & 0.38 & 0.04 & 0.37 & 0.37 & 0.35 & 0.04 \\
\hline Total $t-18: 2$ & $2 \cdot 48$ & $1 \cdot 36$ & 3.63 & $2 \cdot 34$ & 0.52 & 0.07 & 0.86 & 0.09 & 0.85 & 0.78 & 0.53 & 0.04 \\
\hline$t-14: 1 n-5$ & 0.00 & 0.00 & 0.00 & 0.00 & 0.00 & 0.00 & 0.00 & 0.00 & 0.00 & 0.00 & 0.02 & 0.00 \\
\hline$t-16: 1 n-7$ & 0.00 & 0.00 & 0.00 & 0.00 & 0.00 & 0.00 & 0.00 & 0.00 & 0.00 & 0.01 & 0.90 & 0.01 \\
\hline$t-20: 1 n-9$ & 0.00 & 0.00 & 0.00 & 0.00 & 0.00 & 0.01 & 0.00 & 0.00 & 0.02 & 0.04 & 0.00 & 0.00 \\
\hline Total trans fatty acids & $3 \cdot 11$ & $1 \cdot 62$ & $4 \cdot 17$ & $2 \cdot 43$ & $1 \cdot 65$ & 0.68 & $1 \cdot 79$ & 0.24 & $5 \cdot 20$ & $3 \cdot 16$ & $5 \cdot 20$ & 0.20 \\
\hline
\end{tabular}

DPA, docosapentaenoic acid.

affordable price, given the apparently low dietary intake of fish in Bogotá ${ }^{(2)}$. This could be achieved by increasing the content of soyabean oil in the mixtures while avoiding hydrogenation. Because taste was an important reason to choose sunflower oil, special attention to customer preferences should be taken into account when marketing healthy oils. Also, it has been described that lowerincome households give more priority to foods that are 
socially acceptable than to the quality of nutrients in the food $^{(8)}$. Nutrition education campaigns would be needed to help the consumer choose healthy fats. In particular, giving information to the consumers at the point of purchase has been shown to be effective ${ }^{(8)}$. Stricter regulation of advertising health claims is also likely to be a useful strategy to improve people's selection of healthier cooking oils.

We estimate that, overall, $53 \%$ and $23 \%$ of the families used cooking fats with $>2 \%$ and $>4 \%$ trans fatty acids, respectively; while $41 \%$ of the families used cooking fats with $<4 \%$ of $\alpha$-linolenic acid. We did not collect individual information on daily intake of oils and did not analyse the composition of fats used in industrial baking. Therefore, it is not possible to calculate the average individual daily intake of trans fatty acids in this population from our study. None the less, our analysis is still useful to provide valuable information on the composition of the oils consumed by low- and middle-income families in Colombia and the predictors of choosing one type of oil over another. In many developed countries the content of trans fatty acids in fats has decreased considerably $^{(24-28)}$. However, it is not known how current recommendations are affecting the industrial practices in developing countries, where resources are scarce and nutrition policy development and enforcement are difficult to attain. Populations in developing countries are unaware of the quality of fat that they are consuming and how it can affect their health. Governments in Latin American countries are encouraged to adopt PAHO recommendations in order to achieve the Trans-fats free Americas initiative's goals and promote the intake of healthy fats among their populations.

\section{Acknowledgements}

Sources of funding: The work was supported by the David Rockefeller Center for Latin American Studies at Harvard University, the City of Bogotá's Secretary of Education and the National University of Colombia.

Conflict of interest declaration: None.

Authorship responsibilities: design - A.B., M.M.-P., O.C.-R. and E.V.; data analysis - A.B. and E.V.; data collection - O.C.-R., M.M.-P. and S.L.-A.; biochemical analyses - H.C.; manuscript preparation - A.B.; manuscript review - M.M.-P., O.C.-R., S.L.-A., H.C. and E.V.

Acknowledgements: The authors are indebted to the participants and to the field workers for their effort and dedication.

\section{References}

1. Ascherio A \& Willett WC (1997) Health effects of trans fatty acids. Am J Clin Nutr 66, 4 Suppl., 1006S-1010S.

2. World Health Organization (2003) Diet, Nutrition and the Prevention of Chronic Diseases. Report of a Joint FAO/WHO
Expert Consultation. WHO Technical Report Series no. 916. Geneva: WHO.

3. Stender S \& Dyerberg J (2004) Influence of trans fatty acids on health. Ann Nutr Metab 48, 61-66.

4. Pan American Health Organization/World Health Organization Task Force (2007) Trans-fats free Americas. Washington, DC: PAHO/WHO.

5. Salmeron J, Hu FB, Manson JE, Stampfer MJ, Colditz GA, Rimm EB \& Willett WC (2001) Dietary fat intake and risk of type 2 diabetes in women. Am J Clin Nutr 73, 1019-1026.

6. Bray GA, Lovejoy JC, Smith SR, DeLany JP, Lefevre M, Hwang D, Ryan DH \& York DA (2002) The influence of different fats and fatty acids on obesity, insulin resistance and inflammation. J Nutr 132, 2488-2491.

7. Kavanagh K, Jones KL, Sawyer J, Kelley K, Carr JJ, Wagner JD \& Rudell LL (2007) Trans fat diet induces abdominal obesity and changes in insulin sensitivity in monkeys. Obesity (Silver Spring) 15, 1675-1684.

8. Uauy R \& Monteiro CA (2004) The challenge of improving food and nutrition in Latin America. Food Nutr Bull 25, $175-182$.

9. Food and Agriculture Organization of the United Nations (2004) Food balance sheets. FAOSTAT data. http://faostat.fao.org/faostat/ (accessed April 2005).

10. Alcaldía Mayor de Bogotá, Secretaría de Educación (2006) Estadisticas del sector educativode Bogota 2005 y avances 2006. Bogotá: AMdB SdE.

11. Bickel G, Nord M, Price C, Hamilton W \& Cook J (2002) Guide to Measuring Household Food Security, revised 2000. Washington, DC: USDA Food and Nutrition Service.

12. Baylin A, Kabagambe EK, Siles X \& Campos H (2002) Adipose tissue biomarkers of fatty acid intake. Am J Clin Nutr 76, 750-757.

13. Baylin A, Siles X, Donovan-Palmer A, Fernandez X \& Campos H (2007) Fatty acid composition of Costa Rican foods including trans fatty acid content. J Food Compost Anal 20, 182-192.

14. Tavella M, Peterson G, Espeche M, Cavallero E, Cipolla L, Perego L \& Caballero B (2000) Trans fatty acid content of a selection of foods in Argentina. Food Chem 69, 209-213.

15. Henon G, Kemeny Z, Recseg K, Zwobada F \& Kovari K (1999) Deodorization of vegetable oils. Part I: Modelling the geometrical isomerization of polyunsaturated fatty acids. J Am Oil Chem Soc 76, 73-81.

16. Martin CA, Visentainer JV, de Oliveira CC, Matsushita M \& de Souza NE (2006) Trans polyunsaturated fatty acid contents in Brazilian refined soybean oil. Anal Sci 22, 631-633.

17. Lambelet P, Grandgirard A, Gregoire S, Juaneda P, Sebedio JL \& Bertoli C (2003) Formation of modified fatty acids and oxyphytosterols during refining of low erucic acid rapeseed oil. J Agric Food Chem 51, 4284-4290.

18. Block JM \& Barrera-Arellano D (1994) [Hydrogenated products in Brazil: trans isomers, physico-chemical characteristics and fatty acid composition]. Arch Latinoam Nutr 44, 281-285.

19. Eckel RH, Borra S, Lichtenstein AH \& Yin-Piazza SY (2007) Understanding the complexity of trans fatty acid reduction in the American diet: American Heart Association Trans Fat Conference 2006: report of the Trans Fat Conference Planning Group. Circulation 115, 2231-2246.

20. Korver O \& Katan MB (2006) The elimination of trans fats from spreads: how science helped to turn an industry around. Nutr Rev 64, 275-279.

21. Bautista LE, Herran OF \& Pryer JA (2005) Development and simulated validation of a food-frequency questionnaire for the Colombian population. Public Health Nutr 8, 181-188. 
22. Hibbeln JR, Nieminen LR, Blasbalg TL, Riggs JA \& Lands WE (2006) Healthy intakes of $n-3$ and $n-6$ fatty acids: estimations considering worldwide diversity. Am J Clin Nutr 83, 6 Suppl., 1483S-1493S.

23. Williams P (2005) Consumer understanding and use of health claims for foods. Nutr Rev 63, 256-264.

24. Aro A, Van Amelsvoort J, Becker W, van Erp-Baart M-A, Kafatos A, Leth T \& van Poppel G (1998) Trans fatty acids in dietary fats and oils from 14 European countries: The TRANSFAIR Study*1. J Food Compost Anal 11, 137-149.

25. Brat J \& Pokorny J (2000) Fatty acid composition of margarines and cooking fats available on the Czech market. J Food Compost Anal 13, 337-343.
26. Precht D \& Molkentin J (2000) Recent trends in the fatty acid composition of German sunflower margarines, shortenings and cooking fats with emphasis on individual C16:1, C18:1, C18:2, C18:3 and C20:1 trans isomers. Nabrung 44, 222-228.

27. Clifton PM, Keogh JB \& Noakes M (2004) Trans fatty acids in adipose tissue and the food supply are associated with myocardial infarction. J Nutr 134, 874-879.

28. European Food Safety Authority (2004) Opinion of the Scientific Panel on Dietetic Products, Nutrition and Allergies on a request from the Commission related to the presence of trans fatty acids in foods and the effect on human health of the consumption of trans fatty acids. EFSA J 81, 1-49. 